\title{
GluN2D Subunit-Containing NMDA Receptors Control Tissue Plasminogen Activator-Mediated Spatial Memory
}

\author{
Pauline Obiang, ${ }^{1}$ Richard Macrez, ${ }^{1,2}$ Amandine Jullienne, ${ }^{1}$ Thomas Bertrand, ${ }^{1}$ Flavie Lesept, ${ }^{1}$ Carine Ali, ${ }^{1}$ Eric Maubert, ${ }^{1}$ \\ Denis Vivien, ${ }^{1 *}$ and Véronique Agin ${ }^{1 *}$ \\ ${ }^{1}$ Inserm, Mixed Research Unit in Health U919, University Caen Basse Normandie, Serine Proteases and Pathophysiology of the Neurovascular Unit, Public \\ Interest Group CYCERON, F-14074 Caen, France, and 2Department of Neurology, University Hospital of Caen, F-14000 Caen, France
}

Tissue plasminogen activator (tPA) is a serine protease with pleiotropic actions in the CNS, such as synaptic plasticity and neuronal death. Some effects of tPA require its interaction with the GluN1 subunit of the NMDA receptor (NMDAR), leading to a potentiation of NMDAR signaling. We have reported previously that the pro-neurotoxic effect of tPA is mediated through GluN2D subunit-containing NMDARs. Thus, the aim of the present study was to determine whether GluN2D subunit-containing NMDARs drive tPA-mediated cognitive functions. To address this issue, a strategy of immunization designed to prevent the in vivo interaction of tPA with NMDARs and GluN2Ddeficient mice were used in a set of behavioral tasks. Altogether, our data provide the first evidence that tPA influences spatial memory through its preferential interaction with GluN2D subunit-containing NMDARs.

\section{Introduction}

Tissue plasminogen activator (tPA) is a serine protease that promotes thrombolysis in the vascular compartment by converting the zymogen plasminogen into active plasmin (Collen and Lijnen, 1991). In the brain parenchyma, tPA is involved in physiological processes, including synaptic plasticity (Huang et al., 1996; Calabresi et al., 2000; Zhuo et al., 2000; Mataga et al., 2002; Pang et al., 2004) and behaviors (Seeds et al., 1995, 2003; Madani et al., 1999; Pawlak et al., 2002, 2003; Matys et al., 2004; Yamada et al., 2005). tPA also displays important roles in models of acute and chronic brain disorders, such as ischemic brain injury, seizure, and multiple sclerosis (Tsirka et al., 1995; Chen and Strickland 1997; Wang et al., 1998; Wu et al., 2000; Gveric et al., 2001; Lu et al., 2002; Liot et al., 2006).

Several plasminogen-dependent- and -independent mechanisms have been described to explain these multifaceted roles of tPA. For instance, tPA influences some brain functions and dysfunctions by activating plasminogen into plasmin and subsequent degradation of the extracellular matrix (Plow et al., 1995; Chen and Strickland 1997; Wu et al., 2000; Hu et al., 2006) or conversion of the precursor form of brain-derived neurotrophic factor (BDNF) to its mature form (Pang et al., 2004). tPA was also reported to mediate some of its effects through a direct interac-

\footnotetext{
Received Dec. 13, 2011; revised July 17, 2012; accepted July 19, 2012.

Author contributions: C.A., E.M., D.V., and V.A. designed research; P.O., R.M., A.J., T.B., F.L., and E.M. performed research; P.O., E.M., D.V., and V.A. analyzed data; P.O., C.A., D.V., and V.A. wrote the paper.

This work was supported by Inserm, French Ministry of Research and Technology, Regional Council of Lower Normandy, Normandie Appats, and Foundation for Medical Research.

${ }^{*}$ D.V. and V.A. contributed equally to this work.

The authors declare no competing financial interests.

Correspondence should be addressed to Dr. Véronique Agin, Inserm, Mixed Research Unit in Health U919, Serine

Proteases and Pathophysiology of the Neurovascular Unit, Public Interest Group CYCERON, University of Caen Basse Normandie, Boulevard Becquerel, BP 5229, F-14074 Caen, France. E-mail: agin@cyceron.fr.

DOI:10.1523/JNEUROSCI.6202-11.2012

Copyright $\odot 2012$ the authors $\quad 0270-6474 / 12 / 3212726-09 \$ 15.00 / 0$
}

tion with the NMDA receptor (NMDAR) (Nicole et al., 2001; Benchenane et al., 2007).

Seven NMDAR subunits have been characterized in the CNS of mammals: the ubiquitously expressed GluN1 subunit, four GluN2 subunits (GluN2A-GluN2D), and two GluN3 subunits (GluN3A and GluN3B) (Cull-Candy et al., 2001; Kew and Kemp, 2005). More often, NMDARs are hetero-tetrameric assemblies composed of two GluN1 subunits and at least one GluN2 subunit. The GluN3 subunit can coassemble with GluN1/GluN2 complexes. The functional properties of NMDAR channels are in part determined by their subunit composition, in particular, the GluN2 type subunits (Cull-Candy et al., 2001).

We have demonstrated previously that tPA interacts with the GluN1 subunit of NMDARs, a necessary step to enhance NMDAR signaling and subsequent neurotoxicity (Nicole et al., 2001; Fernández-Monreal et al., 2004). Interestingly, a strategy preventing in vivo this $\mathrm{tPA} / \mathrm{GluN1}$ interaction in mice [active immunization against the amino-terminal domain (ATD) of the NMDAR GluN1 subunit] led to a reduced sensitivity to ischemic and excitotoxic neuronal death and impaired cognitive functions, such as spatial memory deficits (Benchenane et al., 2007; Macrez et al., 2010). More recently, we have evidenced by pharmacological and molecular approaches that $\mathrm{PA}$ selectively promotes NMDAR signaling and subsequent neurotoxicity through GluN2D subunit-containing NMDARs (Baron et al., 2010; Jullienne et al., 2011). Thus, to mediate its deleterious functions, tPA interacts with the GluN1 subunit of the NMDAR, a phenomenon occurring preferentially in GluN2D subunit-containing NMDARs.

The aim of the present study was to determine whether GluN2D subunit-containing NMDARs drive tPA-mediated cognitive functions. To address this question, we performed a set of behavioral tasks in wild-type (WT) and GluN2D-deficient mice actively immunized or not to prevent the interaction of tPA with NMDARs. 


\section{Materials and Methods}

\section{Animal experiments}

Experiments were performed in accordance with the French (Decree 87/848) and the European Communities Council (Directive 86/609) guidelines for the care and use of laboratory animals. All efforts were made to minimize animal suffering and the number of animals used.

\section{Subjects}

Homozygous male mutant mice lacking the GluN2D subunit of NMDAR were generated by Prof. Mishina (University of Tokyo, Tokyo, Japan) (Ikeda et al., 1995) and provided by the RIKEN BioResource Center. These homozygous GluN2D mutant mice came from the GluN2D knock-out (KO) strain (RBRC01840), which has a 99.99\% pure C57BL/6 genetic background. The genotype of mice was controlled by PCR using specific primers. Primers 1 and 2 recognize WT allele, and primers 2 and 3 recognize the mutant allele (1, CTTTCAGGGATCTGCCACAAC; 2, CAGACAGTGCCGCAGTCG; 3, TGATATTGCTGAAGAGCTTGG). All WT mice (C57BL/6) and GluN2D-deficient mice (GluN2D KO) used for the behavioral studies were 3-month-old males (20-25 g). Molecular analyses were also performed on 3-month-old male mice weighing 25-30 g (Swiss mice; Janvier). All mice were housed in standard polypropylene cages $(37 \times 23.5 \times 18 \mathrm{~cm}$; Charles River $)$ with access water and food ad libitum (SDS Dietex).

\section{Behavioral tests}

Previous studies have shown that tPA does not influence locomotor activity (Pawlak et al., 2002) but is implicated in emotional and spatial memories (Calabresi et al., 2000; Benchenane et al., 2007; Obiang et al., 2011). Accordingly, we used these behavioral tasks to determine whether the effect of tPA could be mediated by GluN2D subunit-containing NMDARs. All the behavioral tests were performed by an experimenter blinded to the treatment and genotype of the mice.

Locomotor activity. Spontaneous locomotor activity was quantified by using activity cages equipped with horizontal infrared beams located across the long axis of the cage (IMETRONIC). Mice were placed in individual acrylic chambers $(30 \times 20 \times 20 \mathrm{~cm})$ for $60 \mathrm{~min}$. The number of horizontal movements was determined by breaks in movementsensitive photobeams that were then converted into locomotor activity counts.

Contextual fear conditioning. Contextual emotional memory was tested in a conditioning chamber $(67 \times 53 \times 55 \mathrm{~cm}$; Bioseb) constructed from black methacrylate walls and a Plexiglas front door. Floor of the chamber consisted of 22 stainless steel bars ( $3 \mathrm{~mm}$ in diameter, spaced 11 $\mathrm{mm}$ apart, center-to-center) wired to a shock generator with scrambler for the delivery of footshock unconditioned stimulus. Signal generated by the mice movement was recorded and analyzed through a highsensitivity weight transducer system. The analogical signal was transmitted to the Freezing software module through the load cell unit for recording purposes and posterior analysis in terms of activity/immobility. An additional interface associated with corresponding hardware allowed controlling the intensity of the shock from the Freezing software. On the training day, the mice were placed into the conditioning chamber, and they received two shocks in the feet at 2 min intervals after a 2 min acclimatizing period. Each shock was $0.4 \mathrm{~mA}$ and $2 \mathrm{~s}$ duration. Thirty seconds after the final shock, the mice were returned in their home cages. Forty-eight hours or 1 month after the conditioning session, contextual fear memory was assessed by returning the mice to the conditioning chamber and measuring freezing behavior during a 4 min retention test (Obiang et al., 2011). The measurement of fear was performed by considering the freezing time, defined as immobility (i.e., the absence of all movements with the exception of those related to respiration) for a period of at least $500 \mathrm{~ms}$. Contextual fear memory was assessed through the comparison of the percentage of freezing during the retention test normalized to the percentage of freezing during the acclimatizing period of the training session.

Place recognition test. Spatial memory was tested in a gray plastic Y-maze with three identical arms $(34 \times 8 \times 15 \mathrm{~cm})$. Mice were tested after a two-session procedure with a $2 \mathrm{~h} 30$ intersession interval. The length of the rest interval was chosen according to previous studies that have shown that retention of the recognition place task does not last longer than a few hours in mice (Dellu et al., 2000; Obiang et al., 2011). During the acquisition session, one arm was randomly closed with a guillotine door. The position of the closed arm was chosen randomly among the three arms. Each mouse was placed in one of the two other arms (arms 1 and 2, with its head facing away from the center of the maze) and allowed to visit the two accessible arms for $5 \mathrm{~min}$. Mice were then returned to their home cage for $2 \mathrm{~h} 30$, before being subjected to the retention test, in which they had free access to all three arms for $5 \mathrm{~min}$. The number of visits to each arm (considered only when the mouse passed two-thirds of the arm) was recorded for each session. Spatial memory was assessed through the comparison of the percentage of visits in each arm for the $5 \mathrm{~min}$ of the retention test.

\section{Active immunization to prevent the interaction of $\mathrm{PA}$ with the NMDAR GluN1 subunit}

As previously described (Fernández-Monreal et al., 2004; Benchenane et al., 2007), the region of the ATD of the GluN1-1a subunit (amino acids 19-371), corresponding to the domain of interaction with tPA (designed rATD GluN1), was produced from the full-length rat GluN1-1a. rATD was purified from inclusion bodies of isopropyl 1-thio-D galactopyranoside-induced bacterial cultures (Escherichia coli, M15 strain) on a nickel affinity matrix (Qiagen). When GluN2Ddeficient and WT mice were 2 months old, immunization began by intraperitoneal injection of immunogenic mixtures: complete Freund's adjuvant (first injection) and incomplete Freund's adjuvant (once a week during 3 weeks) containing crude lysate of bacterial cultures transformed with a vector containing rATD GluN1 (crude ATD groups) or not (crude control groups). Behavioral tests were performed 2 weeks after the last injection.

\section{Transcardiac perfusion}

Animals were deeply anesthetized with $5 \%$ isoflurane and, thereafter, maintained with $2.5 \%$ isoflurane in a $70 \% / 30 \%$ mixture of $\mathrm{NO}_{2} / \mathrm{O}_{2}$. A transcardiac perfusion was performed with ice-cold $0.9 \% \mathrm{NaCl}$ with $3 \%$ heparin. Then, cortices and hippocampi were carefully harvested for protein and mRNA analyses.

\section{Immunoblotting}

Tissues were dissociated in ice-cold TNT buffer ( $50 \mathrm{~mm}$ Tris- $\mathrm{HCl}, \mathrm{pH}$ 7.4, $150 \mathrm{~mm} \mathrm{NaCl}$, and $0.5 \%$ Triton X-100) at $1 \mathrm{mg} / \mathrm{ml}$. Debris was removed by centrifugation $\left(13,000 \times g\right.$ at $\left.4^{\circ} \mathrm{C}, 15 \mathrm{~min}\right)$. Protein quantification was performed according to the BCA method (Pierce). Proteins $(20 \mu \mathrm{g})$ were resolved on $15 \%$ polyacrylamide gel under denaturing conditions and transferred onto a polyvinylidene difluoride membrane. Membranes were blocked with Tris-buffered saline ( $10 \mathrm{~mm}$ Tris and 200 mM NaCl, pH 7.4) containing $0.05 \%$ Tween 20 and 5\% nonfat dry milk. Blots were incubated overnight with primary antibodies: our mouse $\alpha$ ATD-GluN1 (Macrez et al., 2011) or control IgGs (1:2000), a goat anti-C-terminal domain (CTD)-GluN1 ( $\alpha$ CTD-GluN1, 1:200; Santa Cruz Biotechnology), and a goat anti-CTD-GluN2D $(\alpha$ CTD-GluN2D, 1:200; Santa Cruz Biotechnology). After incubation with the appropriate peroxidase-conjugated secondary antibodies, proteins were visualized with an enhanced chemiluminescence ECL-Plus detection system (PerkinElmer Life and Analytical Sciences).

\section{Primary cultures of cortical neurons}

Cultures were prepared from E15-E16 mouse embryos (Swiss mice; Janvier) as described previously (Baron et al., 2010). Microdissection of cortices was followed by a dissociation of the tissue in a $37^{\circ} \mathrm{C}$ DMEM (Sigma-Aldrich). Cells grew on plates coated with poly-D-lysine $(0.1 \mathrm{mg} /$ $\mathrm{ml})$ and laminin $(0.02 \mathrm{mg} / \mathrm{ml})$ in DMEM supplemented with $5 \%$ horse serum, $5 \%$ fetal bovine serum, and $2 \mathrm{~mm}$ glutamine (Invitrogen). Cells were maintained in a humidified $5 \% \mathrm{CO}_{2}$ atmosphere at $37^{\circ} \mathrm{C}$. To inhibit glial proliferation, cytosine $\beta$-D-arabinoside $(10 \mu \mathrm{M})$ was added after $3 \mathrm{~d}$ in vitro. Neurons were used after $12 \mathrm{~d}$ in vitro.

\section{Calcium video microscopy}

Experiments were performed at room temperature on the stage of a Nikon Eclipse inverted microscope equipped with a $75 \mathrm{~W}$ xenon lamp 
and a Nikon $40 \times, 1.3$ numerical aperture epifluorescence oil-immersion objective. Cell cultures were transferred into a serum-free medium (HBBSS) and loaded with $10 \mu \mathrm{M}$ fura-2 AM (Invitrogen) for $45 \mathrm{~min}$ at $37^{\circ} \mathrm{C}$. Neurons were washed, and NMDA treatment ( $25 \mu \mathrm{M}$ for $30 \mathrm{~s}$ ) was applied using a peristaltic pump. Neurons were then treated for $45 \mathrm{~min}$ with the GluN2D antagonist $\left(2 \mathrm{R}^{\star}, 3 \mathrm{~S}^{\star}\right)$-1-(9-bromophenanthrene-3carbonyl) piperazine-2, 3-dicarboxylic acid (UBP145; $0.2 \mu \mathrm{M}$ ) (Costa et al., 2009), $\alpha$ ATD-GluN1 $(0.01 \mathrm{mg} / \mathrm{ml})$, and tPA $(20 \mu \mathrm{g} / \mathrm{ml})$ either alone or in combination (directly applied in the bathing medium), and again, neurons were exposed to NMDA ( $25 \mu \mathrm{m}$ for $30 \mathrm{~s}$ ). Fura-2 (excitation, 340 and $380 \mathrm{~nm}$; emission, $510 \mathrm{~nm}$ ) ratio images were acquired with a CCD camera (Princeton Instruments) and digitized $(256 \times 512$ pixels $)$ using Metafluor 4.11 software (Universal Imaging Corporation).

\section{Quantitative real-time PCR}

Total RNAs were extracted using Nucleospin RNA II columns (MachereyNagel). Then, RNAs $(1 \mu \mathrm{g})$ were reverse-transcribed using the iScript Select cDNA synthesis kit (reverse transcription: $42^{\circ} \mathrm{C}$ for $1.5 \mathrm{~h}$; Bio-Rad). Primers were designed for each gene using the Beacon Designer software (Bio-Rad). Sequence alignments were performed with the BLAST database to ensure the specificity of primers. The following sequences were used: GluN1 forward primer (F), 5'-CTCTAGCCAGGTCTACGCTATCC-3'; GluN1 reverse primer (R), 5' -GACGGGGATTCTGTAGAAGCCA-3'; GluN2A (F), 5'-AC ATCCACGTTCTTCCAGTTTGG-3'; GluN2A (R), 5' -GACATGCCAGTC ATAGTCCTGC-3'; GluN2B(F), 5'-CCAGAGTGAGAGATGGGATTGC3'; GluN2B (R), 5'-TGGGCTCAGGGATGAAACTGT-3'; GluN2D (F), 5'-CTGTGTGGGTGATGATGTTCGT-3'; and GluN2D (R), 5'-GTGAAGGTAGAGCCTCCGGG-3'.

PCR solutions were prepared with RNase-free water containing primers and IQ SYBR Green Supermix (Bio-Rad). For PCR amplification, 20 $\mu \mathrm{l}$ of mix were added to $5 \mu \mathrm{l}$ of reverse transcription reaction previously diluted (1:20). Two negative controls were performed during each experiment: reactions with no added reverse transcriptase to confirm absence of genomic DNA contamination, and samples with no added cDNA template to confirm absence of primer dimers. Assays were run in triplicate on the iCycler iQ real-time PCR detection system (Bio-Rad). The amplification conditions were as follows: Hot Goldstar enzyme activation, $95^{\circ} \mathrm{C}$ for $3 \mathrm{~min}$; 40 cycles of PCR (denaturation, $95^{\circ} \mathrm{C}, 15 \mathrm{~s}$; hybridization/extension, $60^{\circ} \mathrm{C}, 1 \mathrm{~min}$ ). Relative mRNA transcription was expressed in $2^{- \text {(Ct gene of interest) }}$, in which $\mathrm{Ct}$ is the threshold cycle value.

\section{Data analyses}

Data analyses were conducted with the Systat software package (version 5.02). An $\alpha$ level of $p<0.05$ was used for determination of significance in all statistical tests. All $p$ values are two tailed. For behavioral and molecular analyses, Friedman's tests were used for intragroup multiple comparisons. In significant cases, Wilcoxon's signed-rank tests for matched samples were performed as post hoc tests (Siegel and Castellan 1988). Kruskal-Wallis tests were used for intergroup multiple comparisons. When significant, Mann-Whitney $U$ tests were performed as post hoc tests (Siegel and Castellan 1988). For calcium video microscopy, statisti$\mathrm{cal}$ analyses were performed using paired Student's $t$ test.

\section{Results}

Behavioral phenotype of GluN2D-deficient mice Deficiency in GluN2D subunit reduces spontaneous locomotor activity

GluN2D-deficient mice showed significantly less horizontal movements than their WT littermates (Fig. 1; number of movements, $614 \pm 212$ for WT mice and $466 \pm 105$ for GluN2D KO mice; Mann-Whitney $U$ test, $U=109.500, p<$ $0.05)$. These results show a reduced spontaneous locomotor activity in GluN2D-deficient mice.

Deficiency in GluN2D subunit alters emotional memory

The percentage of freezing in both WT and GluN2D-deficient mice was similar during the acclimatizing period of the training session (Fig. 2A; Mann-Whitney $U$ test, $p>0.05$ ). This means that the emotional state in the two groups was homogeneous.

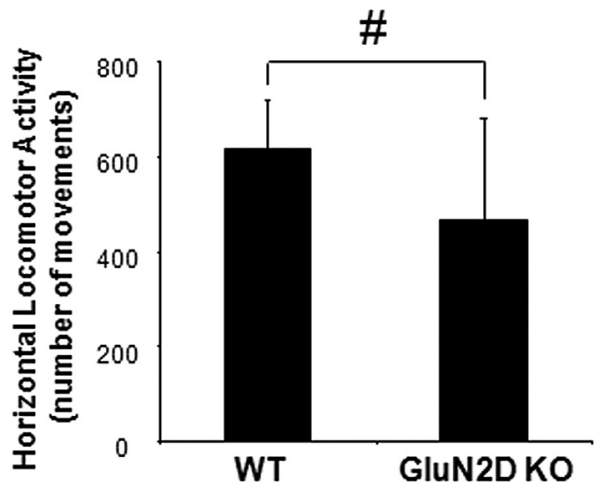

Figure 1. Deficiency in GluN2D subunit reduces spontaneous locomotor activity. Spontaneous locomotor activity was assessed, during $60 \mathrm{~min}$, as the total number of horizontal movements determined by breaks in movement-sensitive photobeams converted into locomotor counts. GluN2D K0 mice, $n=9$; WT mice (WT), $n=10$. Mann-Whitney $U$ test, ${ }^{\#} p<0.05$. Vertical bars indicate SD.

A

Acclimatizing period

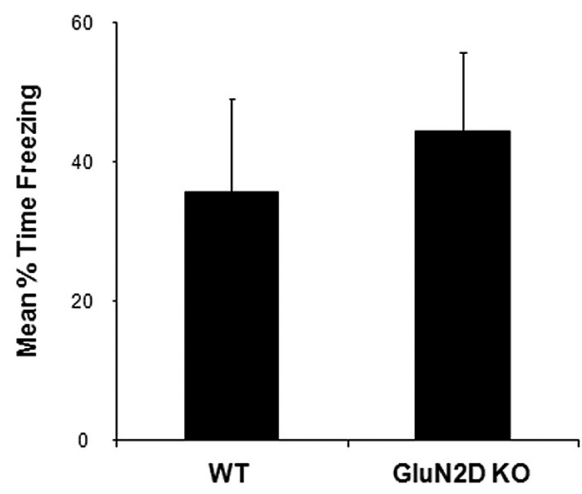

B

$48 \mathrm{H}$ post-training

1 month post-training
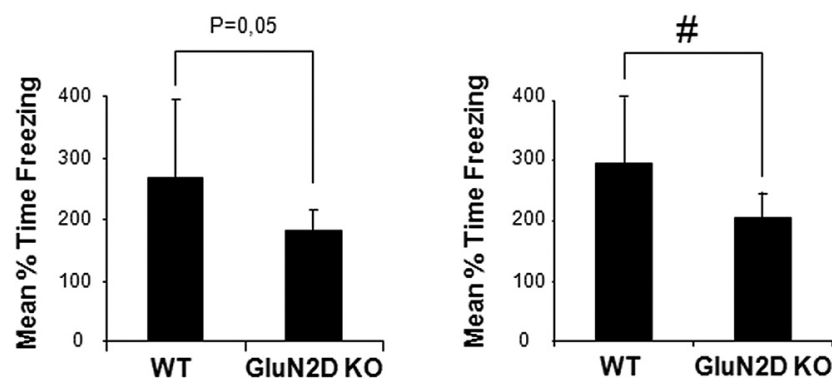

Figure 2. Deficiency in GluN2D subunit alters emotional memory. $\boldsymbol{A}$, Percentage of freezing during the acclimatizing period of the training session of the fear conditioning test. $\boldsymbol{B}$, Retention tests conducted $48 \mathrm{~h}$ and 1 month after conditioning. Contextual emotional memory was assessed as the percentage of freezing during the retention test normalized to the percentage of freezing during the acclimatizing period of the training session. GluN2D KO mice, $n=9$; WT mice (WT), $n=10$. Mann-Whitney $U$ tests, ${ }^{\#} p<$ 0.05. Vertical bars indicate SD.

Forty-eight hours or 1 month after the training session, contextual emotional memory was assessed by returning the mice in the conditioning chamber and by measuring the freezing behavior during the $4 \mathrm{~min}$ of the retention test. GluN2D-deficient mice showed less fear because they took significantly less time to freeze than the WT mice (Fig. $2 \mathrm{~B}$; Mann-Whitney $U$ tests: $48 \mathrm{~h}$ after training, $U=69, p=0.05 ; 1$ month after training, $U=71, p<$ 
A

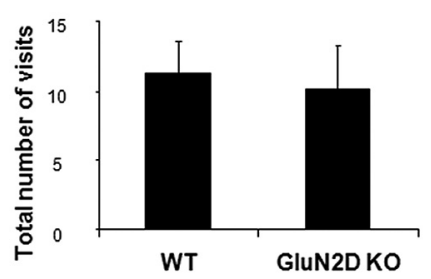

B
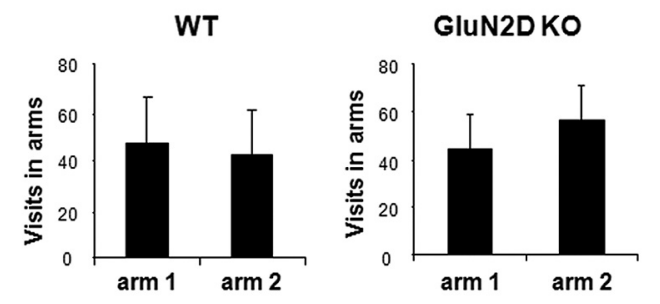

C WT
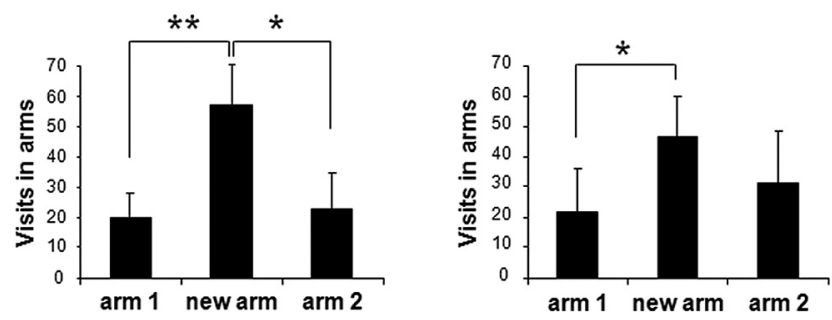

Figure 3. Deficiency in GluN2D subunit alters spatial memory. Total number of visits $(\boldsymbol{A})$ and percentage of visits $(\boldsymbol{B})$ in arms 1 and 2 during the acquisition session of the place recognition task. C, Retention test was conducted after a $2 \mathrm{~h} 30$ rest interval. Spatial memory was assessed through the comparison of the percentage of visits in each arm for $5 \mathrm{~min}$ of the retention test. GluN2D K0 mice, $n=9$; WT mice (WT), $n=10$. Wilcoxon's signed-rank tests, ${ }^{*} p<0.05$, ${ }^{* *} p<0.01$. Vertical bars indicate SD.

0.05). These results indicate that deficiency in GluN2D subunit impairs contextual fear memory.

Deficiency in GluN2D subunit alters spatial memory

During the acquisition session, the total number of visits in the two free access arms of the Y-maze was similar between GluN2Ddeficient mice and their WT littermates (Fig. 3A; Mann-Whitney $U$ test, $p>0.05)$. Moreover, both groups visited arm 1 as often as arm 2 (Fig. 3B; Wilcoxon's signed-rank tests: WT mice, arm 1 vs $\operatorname{arm} 2, p>0.05$; GluN2D KO mice, arm 1 vs arm 2, $p>0.05$ ). However, during the retention session, although WT mice correctly discriminated the newly open arm and the two familiar arms (Fig. 3C; Wilcoxon's signed-rank tests: arm 1 vs new arm, $Z=2.677, p<$ 0.01; arm 2 vs new arm, $Z=2.539, p<0.05$ ), GluN2D-deficient mice failed to discriminate arm 2 and the newly open arm (Fig. $3 C$; Wilcoxon's signed-rank tests: arm 1 vs new arm, $Z=2.399, p<0.05$; arm 2 vs new arm, $p>0.05$ ). These results show a deficit of spatial memory in GluN2D-deficient mice.

Active immunization selectively prevents tPA/GluN1 interaction and TPA-induced enhancement of NMDAR signaling without altering the basal NMDAR signaling Here, we used a strategy of active immunization raised against the recombinant form of the ATD of the NMDAR GluN1 subunit (ATD-GluN1; Fig. 4A), reported previously to prevent the interaction of tPA with GluN1 subunit, and subsequent action of tPA on NMDAR signaling. IgGs purified from plasma harvested from both control and ATD-GluN1 immunized mice (control IgGs and $\alpha$ ATD-GluN1, respectively) were used to reveal immunob-

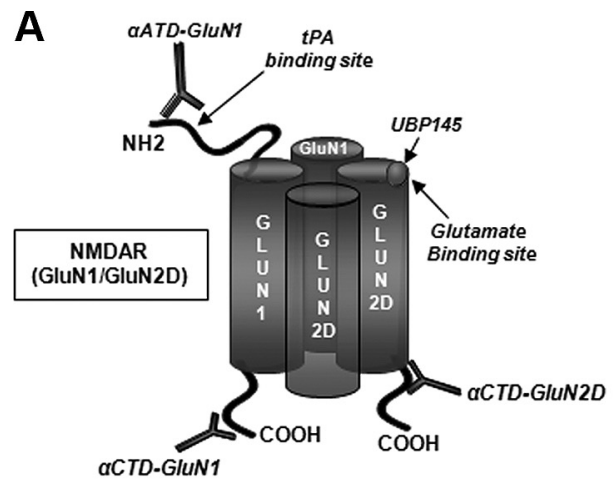

B
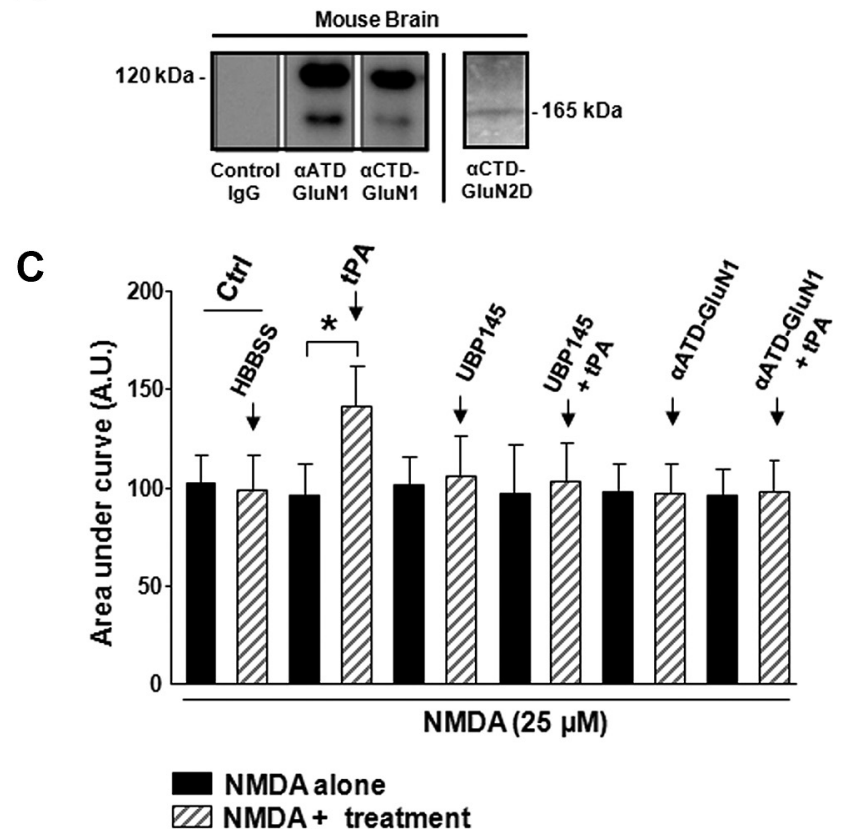

Figure 4. Active immunization selectively prevents $\mathrm{PAA} / \mathrm{GluN1}$ interaction and $\mathrm{tPA}$-induced enhancement of NMDAR signaling without altering the basal $\mathrm{Ca}^{2+}$ conductivity. $A$, Schematic representation of NMDAR composed of GluN1/GluN2D subunits, including binding sites of $\alpha$ ATD-GluN1, $\alpha$ CTD-GluN1, and $\alpha$ CTD-GluN2D antibodies, UBP145, and TPA. B, ATD-GluN1 immunized mice display antibodies specifically targeting the GluN1 subunit of NMDAR. Proteins extracts from naive mouse brain $(n=3)$ were subjected to immunoblots revealed with lgGs purified from either control mice (control lgGs) or ATD-GluN1 (120 kDa) immunized mice ( $\alpha$ ATD-GluN1). Parallel immunoblottings were performed and revealed with antibodies raised against either (TD-GluN1 (named $\alpha$ (TD-GluN1), known to reveal a band at $\sim 120 \mathrm{kDa}$, or CTD-GluN2D (named $\alpha$ CTD-GluN2D), known to reveal a band at $\sim 165$ kDa. C, After immunization, mice display circulating antibodies against GluN1, capable of preventing the potentiating effect of tPA on GluN1/GluN2D subunit-containing NMDARs. NMDA induces $\mathrm{Ca}^{2+}$ influx in cortical neurons as measured by fura- 2 video microscopy $(N=3, n=150$ cells). Coapplication of tPA ( $20 \mu \mathrm{g} / \mathrm{ml} ; 45 \mathrm{~min})$ potentiates the NMDA-evoked Ca ${ }^{2+}$ influx by $47 \%(N=3, n=108$ cells). Neither UBP145 alone ( $0.2 \mu \mathrm{m} ; N=3, n=150$ cells) nor $\alpha$ ATD-GluN1 antibodies alone $\left(0.01 \mathrm{mg} / \mathrm{ml} ; N=3, n=108\right.$ cells) alter NMDA-induced $\mathrm{Ca}^{2+}$ influx. Both UBP145 $(0.2 \mu \mathrm{m})$ and $\alpha$ ATD-GluN1 $(0.01 \mathrm{mg} / \mathrm{ml})$ are capable of blocking this potentiating effect of $\mathrm{tPA}(N=3$, $n=150$ cells and $N=3, n=108$ cells, respectively). Ctrl, Control; HBBSS, serum-free medium. Paired Student's $t$ test (before vs after treatment), ${ }^{*} p<0.001$. Vertical bars indicate SD.

lottings using naive mouse brain extracts as sample. Figure $4 B$ shows that ATD-GluN1 antibodies ( $\alpha$ ATD-GluN1) reveal fulllength GluN1 (and not GluN2D). Control immunoblottings revealed with commercially available antibodies for GluN1 $(\alpha$ CTD-GluN1) and GluN2D ( $\alpha$ CTD-GluN2D) were performed in parallel as controls (Fig. $4 B$ ).

We then determined whether these ATD-GluN1 antibodies were capable to block the interaction and the potentiating effect of tPA on 
A

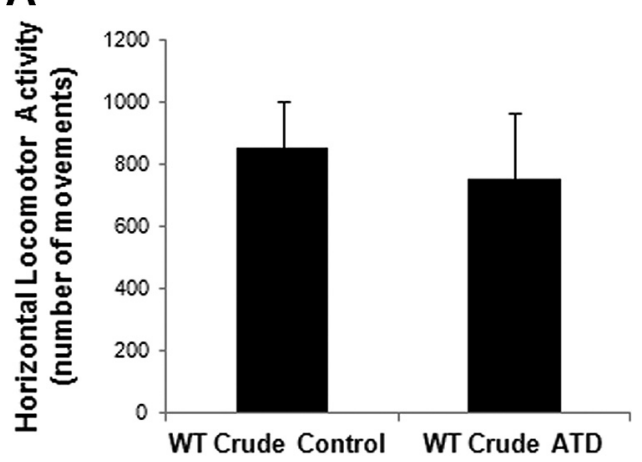

B

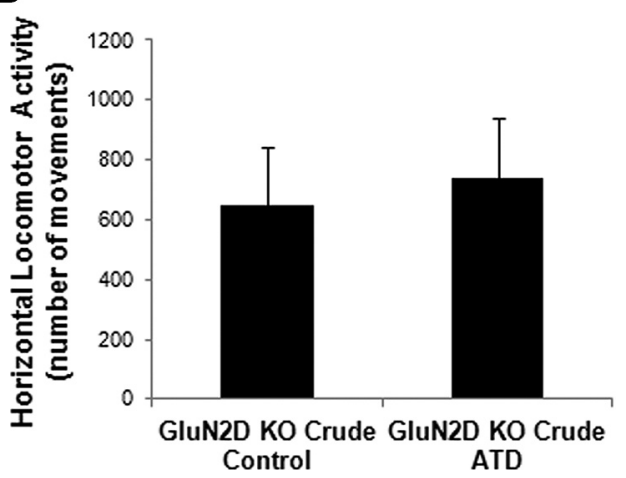

Figure 5. Immunization targeting the tPA/GluN1 interaction does not affect spontaneous locomotor activity in WT $(\boldsymbol{A})$ and GluN2D-deficient $(\boldsymbol{B})$ mice. Spontaneous locomotor activity was assessed, during $60 \mathrm{~min}$, as the total number of horizontal movements determined by breaks in movement-sensitive photobeams converted into locomotor counts. WT Crude ATD mice, $n=11$; Crude Control mice, $n=10$; GluN2D KO Crude ATD mice, $n=13$; GluN2D KO Crude Control mice, $n=12$. Vertical bars indicate SD.

GluN1/GluN2D subunit-containing NMDARs. Thus, NMDAinduced calcium influx was recorded on primary cultures of cortical neurons (Fig. 4C). Although tPA promotes NMDA-induced calcium influx ( $+47 \%$; Fig. $4 C$; paired Student's $t$ test, $p<0.001$ ), coincubation of tPA with ATD-GluN1 antibodies completely prevented the potentiating effect of tPA (Fig. 4C; paired Student's $t$ test, $p>0.05$ ), as observed with a GluN2D receptor antagonist (UBP145; Fig. $4 C$; paired Student's $t$ test, $p>0.05$ ). Importantly, the ATDGluN1 antibodies, when applied alone, did not influence basal NMDAR activity (Fig. 4C; paired Student's $t$ test, $p>0.05$ ).

Immunization targeting the tPA/GluN1 interaction affects neither spontaneous locomotor activity nor emotional memory in WT and GluN2D-deficient mice

Spontaneous locomotor activity was similar between control (WT crude control) and immunized WT (WT crude ATD; Fig. 5A; number of movements, $848 \pm 154$ for WT crude control and $750 \pm 211$ for WT crude ATD; Mann-Whitney $U$ test, $p>0.05)$ mice. These results indicate that the $\mathrm{PA} / \mathrm{GluN1}$ interaction is not involved in spontaneous locomotor activity. Similar results were obtained for GluN2D-deficient mice (Fig. 5B; number of movements, $644 \pm 197$ for GluN2D KO crude control and 736 \pm 204 for GluN2D KO crude ATD; Mann-Whitney $U$ test, $p>0.05$ ).

WT and GluN2D-deficient mice, immunized or not, showed similar percentages of freezing during the acclimatizing period of the training session (Fig. $6 A$; Mann-Whitney $U$ test, $p>0.05$ ) showing that the emotional state in the control and immunized groups was homogeneous. Interestingly, $48 \mathrm{~h}$ or $1 \mathrm{month}$ after training, immunized WT mice (WT crude ATD) submitted to the retention tests

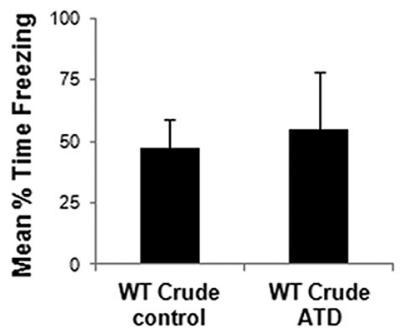

B $48 \mathrm{H}$ post-training

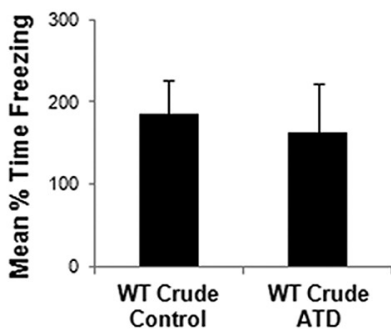

C

$48 \mathrm{H}$ post-training
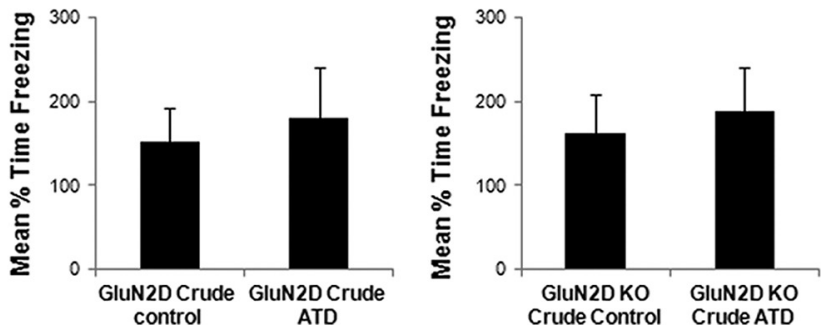

Figure 6. Immunization targeting the $\mathrm{PAA} / \mathrm{GluN1}$ interaction does not affect emotional memory in WT and GluN2D-deficient mice. $A$, Percentage of freezing during the acclimatizing period of the training session of the fear conditioning test. $B, C$, Retention tests conducted $48 \mathrm{~h}$ and 1 month after conditioning. Contextual emotional memory was assessed as the percentage of freezing during the retention test normalized to the percentage of freezing during the exploration of the training session. WT Crude ATD mice, $n=11$; WT Crude Control mice $n=10$; GluN2D K0 Crude ATD mice, $n=13$; GluN2D KO Crude Control mice, $n=12$. Vertical bars indicate SD.

showed a time of freezing similar to their control counterparts (WT crude control; Fig. $6 B$; Mann-Whitney $U$ tests: $48 \mathrm{~h}$ after training, $p>0.05 ; 1$ month after training, $p>0.05$ ). These results indicate that the tPA/GluN1 interaction is not involved in contextual fear memory. Similar results were obtained for GluN2D-deficient mice (Fig. 6C; Mann-Whitney $U$ tests: $48 \mathrm{~h}$ after training, $p>0.05 ; 1$ month after training, $p>0.05$ ).

Altogether, these results show that locomotor activity and contextual fear memory, reported previously to be mediated by GluN2D subunit-containing NMDARs (Figs. 1, 2), are not impaired as a consequence of the immunization protocol targeting GluN1 subunit.

Although immunization targeting tPA/GluN1 interaction specifically alters spatial memory in WT mice, it fails to affect spatial memory in GluN2D-deficient mice

During the acquisition session, the total number of visits in the two free access arms of the Y-maze was similar between WT control (WT crude control) and immunized WT (WT crude ATD; Fig. 7A; Mann-Whitney $U$ test, $p>0.05)$ mice. In addition, both groups visited the two arms equally (Fig. $7 B$; Wilcoxon's signed rank tests: WT crude control, arm 1 vs arm 2, $p>0.05$; WT 
A
WT

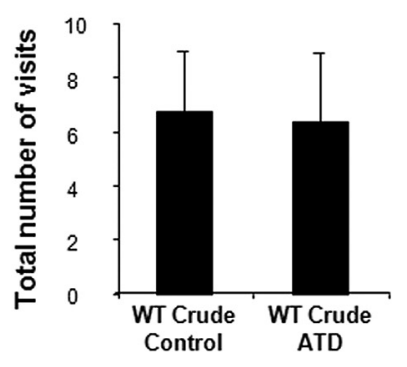

B
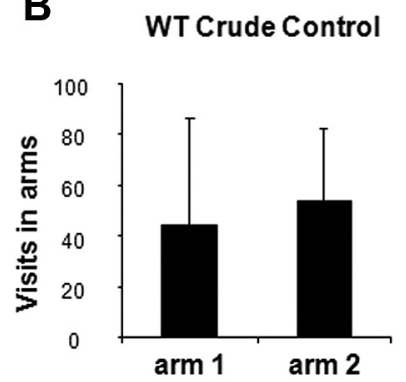

GluN2D KO Crude Control

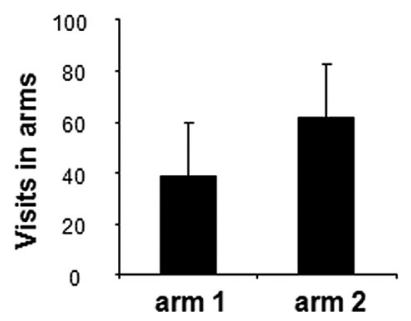

GluN2D KO

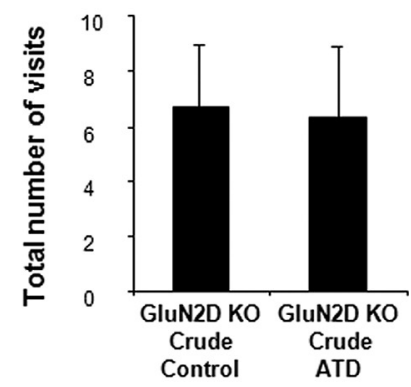

WT Crude ATD

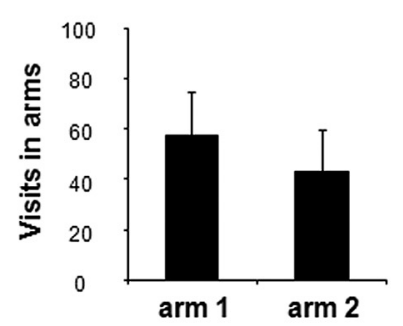

GluN2D KO Crude ATD

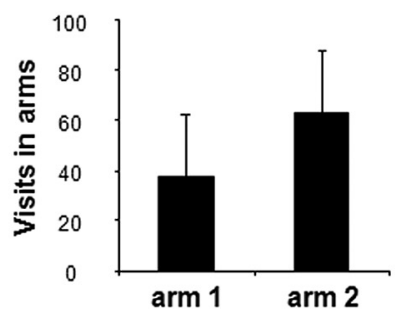

Figure 7. Immunization targeting the tPA/GluN1 interaction does not affect acquisition performance of WT and GluN2D-deficient mice in the place recognition task. $A$, Total number of visits in arms 1 and 2. B, Percentage of visits in arms 1 and 2. WT Crude ATD mice, $n=11$; WT Crude Control mice, $n=10$; GluN2D KOCrude ATD mice, $n=13$; GluN2D KO Crude Control mice, $n=12$. Vertical bars indicate SD.

4crude ATD, arm 1 vs arm $2, p>0.05)$. Similar results were obtained in control (GluN2D KO crude control) and immunized (GluN2D KO crude ATD) GluN2D-deficient mice (Fig. 7A; Mann-Whitney $U$ test, $p>0.05$; Fig. 7B; Wilcoxon's signed-rank tests: GluN2D KO crude control, arm 1 vs arm 2, $p>0.05$; GluN2D crude ATD, arm 1 vs arm 2, $p>0.05$ ).

Interestingly, spatial memory of WT mice was totally inhibited after immunization, preventing the interaction of tPA with NMDAR. Indeed, immunized WT mice (WT crude ATD) did not discriminate between the three arms, whereas control animals (WT crude control) were able to recognize the familiar arms from the newly open arm (Fig. $8 \mathrm{~A}$; Wilcoxon's signed-rank tests: WT crude control, arm 1 vs new arm, $Z=2.812, p<0.01$; arm 2 vs new arm, $Z=2.325, p<0.05$; WT crude ATD, arm 1 vs new arm, $p>0.05$; arm 2 vs new arm, $p>0.05$ ). These results suggest that the $\mathrm{tPA} / \mathrm{GluN} 1$ interaction is required for the achievement of the spatial memory. In contrast, the blockage of the tPA/GluN1 interaction in GluN2D-deficient mice (GluN2D KO crude ATD) did not aggravate the deficit of spatial memory observed previously in the non-immunized GluN2D-deficient mice (GluN2D KO crude control; Fig. $8 B$; Wilcoxon's signed-rank tests: GluN2D KO crude control, arm 1 vs new arm, $Z=2.666, p<$
A
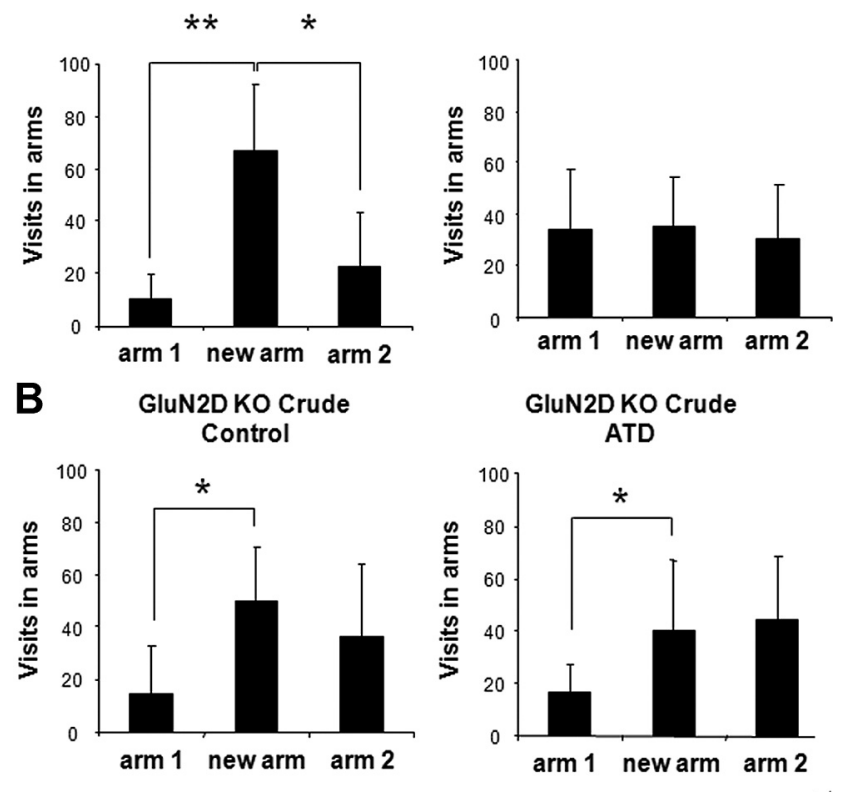

Figure 8. Although immunization targeting $\mathrm{PAA} / \mathrm{GluN1}$ interaction alters spatial memory in WT mice $(\boldsymbol{A})$, it fails to affect spatial memory in GluN2D-deficient mice $(\boldsymbol{B})$. Retention test was conducted after a $2 \mathrm{~h} 30$ rest interval. Spatial memory was assessed through the comparison of the percentage of visits in each arm for the 5 min of the retention test. Immunized WT mice (WT Crude ATD), $n=11$; control WT mice (WT Crude Control), $n=10$; GluN2D KO Crude ATD mice $n=13$; GluN2D KO Crude Control, $n=12$. Wilcoxon's signed-rank tests, ${ }^{*} p<0.05$; ${ }^{* *} p<0.01$. Vertical bars indicate SD.
A

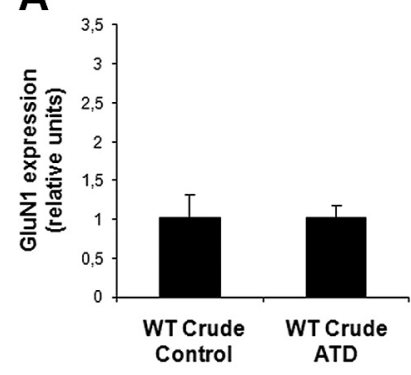

C

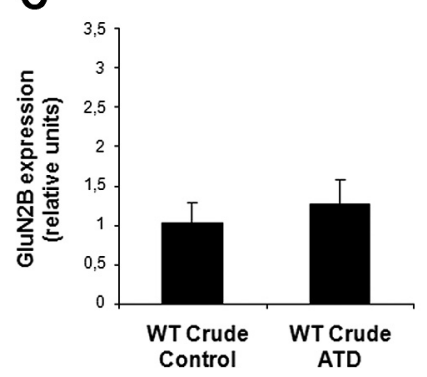

B

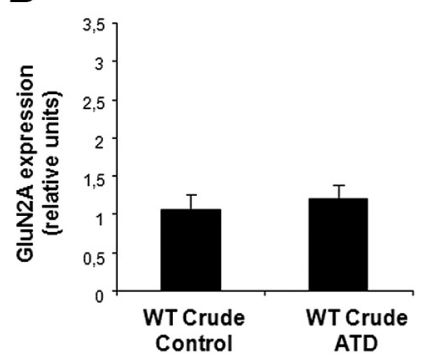

D

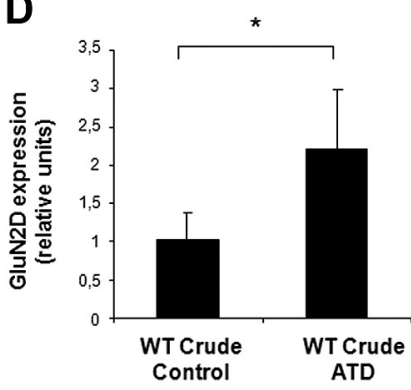

Figure 9. Regulation of NMDAR subunits (GluN1, GluN2A, GluN2B, GluN2D) in hippocampus after active immunization against the ATD of the NMDAR GluN1 subunit. Relative mRNA quantity, estimated by RT-qPCR, was expressed in $2^{- \text {(Ct gene of interest) }}$, in which $\mathrm{Ct}$ is the threshold cycle value. $A$, GluN1 subunit mRNA expression. $B$, GluN2A subunit mRNA expression. $C$, GluN2B subunit mRNA expression. $D$, GluN2D subunit mRNA expression. WT Crude ATD mice, $n=5$; WT Crude Control mice, $n=5$. Mann-Whitney $U$ test, ${ }^{*} p<0.05$. Vertical bars indicate SD.

0.05 ; arm 2 vs new arm, $p>0.05$; GluN2D KO crude ATD, arm 1 vs new arm, $Z=2.198, p<0.05$; $\operatorname{arm} 2$ vs new arm, $p>0.05$ ). These data reveal that mice lacking GluN2D subunit are resistant to inhibition of tPA/GluN1 interaction-induced spatial 
memory impairment, suggesting that tPA-dependent impairment of spatial memory involves a GluN2D subunitdependent mechanism.

These results cannot be explained by nonspecific effects of the immunization strategy because the expression of NMDAR was not changed in the hippocampus, a cerebral structure involved in spatial memory. Indeed, the in vivo distribution of the different NMDA subunits was determined by quantitative PCR in hippocampi of control and ATD-GluN1 immunized mice (Fig. 9). The data show that our strategy of immunization against the NMDAR GluN1 subunit failed to influence the endogenous expression of GluN1, GluN2A, and GluN2B (Fig. 9; Mann-Whitney $U$ test, $p>0.05$ ). As a feedback response to the blockage of the interaction of tPA with GluN1/GluN2D subunit-containing NMDAR, a weak increase in the expression of GluN2D was observed (Fig. 9; Mann-Whitney $U$ test, $U=$ $2, p<0.05)$. This increased expression of GluN2D could be a tentative mechanism of compensation. However, it does not modify the previously reported GluN2D-dependent behaviors in immunized WT mice when compared with their non-immunized littermates (i.e., horizontal locomotor activity, Figs. 1,5A; contextual fear conditioning, Figs. 2, 6A, $B)$.

Figure 10 provides a summary of the behavioral data obtained. $A-C$ depict, respectively, the behaviors influenced by $\mathrm{tPA}$, those affected by the blockage of the interaction of tPA with the GluN1/ GluN2D subunit-containing NMDAR in WT mice, and those affected by the blockage of the interaction of TPA with NMDAR in the GluN2D-deficient mice. Together, our data show for the first time that the GluN1/GluN2D subunit-containing NMDAR drives the effects of tPA on spatial memory.

\section{Discussion}

In the brain parenchyma, tPA has been identified as a key player in numerous physiological and pathological processes. For example, tPA is involved in synaptic plasticity processes (Mataga et al., 2002), such as long-term potentiation (Huang et al., 1996; Pang et al., 2004) and long-term depression (Calabresi et al., 2000). Accordingly, tPA has been implicated in numerous behaviors, including various forms of learning and emotional behaviors (Seeds et al., 1995; Madani et al., 1999; Calabresi et al., 2000; Pawlak et al., 2002, 2003; Seeds et al., 2003; Benchenane et al., 2007). Apart from these physiological functions, tPA was reported to influence neuronal, oligodendrocytic, and endothelial death/survival after excitotoxic, apoptotic, and/or inflammatory challenges (Chen and Strickland 1997; Wang et al., 1998; Nicole et al., 2001; Liu et al., 2004a; Liot et al., 2006; Correa et al., 2011).

Among the mechanisms advanced to explain these actions of tPA, its interaction with the GluN1 subunit of the NMDAR, leading to a potentiation of NMDA-mediated calcium influx, has been evidenced by several groups (Nicole et al., 2001; FernándezMonreal et al., 2004; Kvajo et al., 2004; Samson et al., 2008; Nassar et al., 2010). Alternatively, it has been proposed that tPA could modulate NMDAR-mediated signaling through the
A

B

C

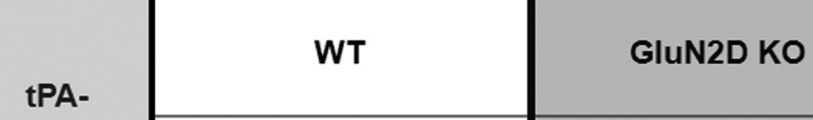

fluenced

Behavior

tPA/NMDAR interaction

\begin{tabular}{|l|l|l|l|}
\hline NORMAL & INHIBITION & NORMAL & INHIBITION \\
\hline
\end{tabular}

\begin{tabular}{l|l|l|l} 
NO & & &
\end{tabular}

YES

alabresietal

2000)

YES

chenane etal

2007)

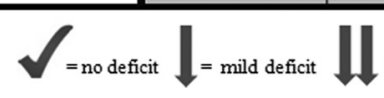

dies have evidenced that tPA was not involved in locomotor activity (Pawlak et al., 2002). However, tPA is known to influence both emotional (Calabresi et al., 2000) and spatial memories (Benchenane et al., 2007). B, Our present experiments reveal that inhibition of the 列 raction does not impair the spatial memory in GluN2D KO mice. Together, these results demonstrate that tPA influences spatia

GluN2B subunit (Pawlak et al., 2005) or lipoprotein receptorrelated protein (Samson et al., 2008).

Because we have identified the exact location of the interaction of tPA within GluN1 in cultured cortical neurons (Fernández-Monreal et al., 2004), we performed active immunization leading to the production of antibodies recognizing the ATD of GluN1 (Benchenane et al., 2007; Macrez et al., 2010). Importantly, these antibodies do not alter NMDA-induced basal neurotransmission (toxicity, calcium influx), but they specifically block the potentiating effect of tPA on these receptors. Accordingly, we have shown that this strategy of blockage of the tPA/GluN1 interaction leads to behavioral deficits in Swiss mice and also prevents the pro-neurotoxicity of tPA both in vitro and in vivo (Benchenane et al., 2007; Macrez et al., 2010). In addition, in recent studies, we evidenced both in vitro and in vivo that the pro-neurotoxic effect of tPA was mediated by GluN2D subunitcontaining NMDAR (Baron et al., 2010; Jullienne et al., 2011), suggesting that, although tPA interacts with the GluN1 subunit, this mechanism occurs preferentially in GluN2D subunitcontaining NMDAR. Obviously, this interesting new question will need to be clarified in future studies.

Thus, the first step of our present study was to confirm (Ikeda et al., 1995; Miyamoto et al., 2002; Hagino et al., 2010) and extend the behavioral phenotype of GluN2D-deficient mice by the use of various tests, such as actimetry, contextual fear conditioning, and place recognition task. Our results show a decrease in spontaneous locomotor activity and in emotional memory in GluN2Ddeficient mice as described previously by other authors (Ikeda et al., 1995; Miyamoto et al., 2002; Hagino et al., 2010). In addition, we evidenced that GluN2D-deficient mice exhibited low performances in the place recognition task because they do not discriminate the newly open arm and one familiar arm. We thus provide 
here the first evidence linking the GluN2D subunit of the NMDAR to the regulation of spatial memory.

We then tested the effects of immunization preventing in vivo the tPA/GluN1 interaction (Benchenane et al., 2007) in WT and GluN2D-deficient mice in the same behavioral tasks. Our data demonstrate that the blockage of the interaction of tPA with NMDAR influences neither locomotor behavior nor emotional memory, suggesting that tPA/GluN1 interaction is not involved in such behaviors in mice. In contrast, in the Y-maze task, immunized WT mice (WT crude ATD) do not discriminate between the newly open arm and the two familiar arms, showing a high alteration of spatial memory. These results demonstrate that the tPA/GluN1 interaction mediates the place recognition task used in this study. These data obtained in C57BL/6 mice are in agreement with our previous work performed on Swiss mice (Benchenane et al., 2007), showing then the phenotypic consistency of the mechanism across these mouse strains. In addition, our present data reveal that, although NMDARs are involved in emotional memory (Levenson et al., 2002; Bardgett et al., 2003; Gao et al., 2010), the influence of tPA on this process cannot be explained by its ability to promote NMDAR-dependent signaling. It is well admitted that the establishment of emotional memory also involves BDNF (Liu et al., 2004b). Interestingly, the maturation of BDNF critically depends on tPA activity (Pang et al., 2004; Obiang et al., 2011). Thus, it is possible that the influence of tPA on emotional memory is based only on its implication in the maturation of BDNF.

Finally, based on our proposed mechanism of action in which tPA mediates some of its effects through GluN2D subunitcontaining NMDARs (Baron et al., 2010; Jullienne et al., 2011), we used the same strategy of immunization in GluN2D-deficient mice and studied the functional consequences in the place recognition task. Interestingly, blockage of the interaction of tPA with NMDAR does not affect further the spatial memory deficits of the GluN2D-deficient mice (GluN2D KO crude ATD) compared with non-immunized GluN2D-deficient mice (GluN2D KO crude control). Moreover, the memory performances of immunized GluN2D-deficient mice are better than those of immunized WT mice, which are not able to discriminate the three arms. Thus, these results provide in vivo evidences that the impairment found in WT mice in the Y-maze behavioral task is a consequence of the lack of tPA interaction with GluN1/GluN2D subunitcontaining NMDARs.

Altogether, we provide here the first evidence that binding of tPA to GluN2D subunit-containing NMDARs mediates some tPA-influenced behaviors. The relevance of the link between tPA and GluN2D might require additional evidences, such as further studies using specific GluN2D antagonists, or genetic means, but none of those strategies are available yet. Future studies should contribute to the characterization of neuronal networks underlying the functional consequences of the interaction of tPA with the GluN1/GluN2D subunit-containing NMDARs.

\section{References}

Bardgett ME, Boeckman R, Krochmal D, Fernando H, Ahrens R, Csernansky JG (2003) NMDA receptor blockade and hippocampal neuronal loss impair fear conditioning and position habit reversal in C57Bl/6 mice. Brain Res Bull 60:131-142.

Baron A, Montagne A, Cassé F, Launay S, Maubert E, Ali C, Vivien D (2010) NR2D-containing NMDA receptors mediate tissue plasminogen activatorpromoted neuronal excitotoxicity. Cell Death Differ 17:860-871.

Benchenane K, Castel H, Boulouard M, Bluthé R, Fernandez-Monreal M, Roussel BD, Lopez-Atalaya JP, Butt-Gueulle S, Agin V, Maubert E, Dantzer R, Touzani O, Dauphin F, Vivien D, Ali C (2007) Anti-NR1
$\mathrm{N}$-terminal-domain vaccination unmasks the crucial action of tPA on NMDA-receptor-mediated toxicity and spatial memory. J Cell Sci 120:578-585.

Calabresi P, Napolitano M, Centonze D, Marfia GA, Gubellini P, Teule MA, Berretta N, Bernardi G, Frati L, Tolu M, Gulino A (2000) Tissue plasminogen activator controls multiple forms of synaptic plasticity and memory. Eur J Neurosci 12:1002-1012.

Chen ZL, Strickland S (1997) Neuronal death in the hippocampus is promoted by plasmin-catalyzed degradation of laminin. Cell 91:917-925.

Collen D, Lijnen HR (1991) Basic and clinical aspects of fibrinolysis and thrombolysis. Blood 78:3114-3124.

Correa F, Gauberti M, Parcq J, Macrez R, Hommet Y, Obiang P, Hernangómez M, Montagne A, Liot G, Guaza C, Maubert E, Ali C, Vivien D, Docagne F (2011) Tissue plasminogen activator prevents white matter damage following stroke. J Exp Med 208:1229-1242.

Costa BM, Feng B, Tsintsadze TS, Morley RM, Irvine MW, Tsintsadze V, Lozovaya NA, Jane DE, Monaghan DT (2009) N-methyl-D-aspartate (NMDA) receptor NR2 subunit selectivity of a series of novel piperazine2,3-dicarboxylate derivatives: preferential blockade of extrasynaptic NMDA receptors in the rat hippocampal CA3-CA1 synapse. J Pharmacol Exp Ther 331:618-626.

Cull-Candy S, Brickley S, Farrant M (2001) NMDA receptor subunits: diversity, development and disease. Curr Opin Neurobiol 11:327-335.

Dellu F, Contarino A, Simon H, Koob GF, Gold LH (2000) Genetic differences in response to novelty and spatial memory using a two-trial recognition task in mice. Neurobiol Learn Mem 73:31-48.

Fernández-Monreal M, López-Atalaya JP, Benchenane K, Cacquevel M, Dulin F, Le Caer JP, Rossier J, Jarrige AC, Mackenzie ET, Colloc'h N, Ali C, Vivien D (2004) Arginine 260 of the amino-terminal domain of NR1 subunit is critical for tissue-type plasminogen activator-mediated enhancement of $N$-methyl-D-aspartate receptor signaling. J Biol Chem 279:50850-50856.

Gao C, Gill MB, Tronson NC, Guedea AL, Guzmán YF, Huh KH, Corcoran KA, Swanson GT, Radulovic J (2010) Hippocampal NMDA receptor subunits differentially regulate fear memory formation and neuronal signal propagation. Hippocampus 20:1072-1082.

Gveric D, Hanemaaijer R, Newcombe J, van Lent NA, Sier CF, Cuzner ML (2001) Plasminogen activators in multiple sclerosis lesions: implications for the inflammatory response and axonal damage. Brain 124:1978-1988.

Hagino Y, Kasai S, Han W, Yamamoto H, Nabeshima T, Mishina M, Ikeda K (2010) Essential role of NMDA receptor channel $\varepsilon 4$ subunit (GluN2D) in the effects of phencyclidine, but not methamphetamine. PLoS One 5:e13722.

Hu K, Yang J, Tanaka S, Gonias SL, Mars WM, Liu Y (2006) Tissue-type plasminogen activator acts as a cytokine that triggers intracellular signal transduction and induces matrix metalloproteinase-9 gene expression. J Biol Chem 281:2120-2127.

Huang YY, Bach ME, Lipp HP, Zhuo M, Wolfer DP, Hawkins RD, Schoonjans L, Kandel ER, Godfraind JM, Mulligan R, Collen D, Carmeliet $\mathrm{P}$ (1996) Mice lacking the gene encoding tissue-type plasminogen activator show a selective interference with late-phase long-term potentiation in both Schaffer collateral and mossy fiber pathways. Proc Natl Acad Sci U S A 93:8699-8704.

Ikeda K, Araki K, Takayama C, Inoue Y, Yagi T, Aizawa S, Mishina M (1995) Reduced spontaneous activity of mice defective in the epsilon 4 subunit of the NMDA. Brain Res Mol Brain Res 33:61-71.

Jullienne A, Montagne A, Orset C, Lesept F, Jane DE, Monaghan DT, Maubert E, Vivien D, Ali C (2011) Selective inhibition of GluN2D-containing $N$-methyl-D-aspartate receptors prevents tissue plasminogen activatorpromoted neurotoxicity both in vitro and in vivo. Mol Neurodegener 6:68.

Kew JN, Kemp JA (2005) Ionotropic and metabotropic glutamate receptor structure and pharmacology. Psychopharmacology (Berl) [Erratum (2005) 182:320] 179:4-29.

Kvajo M, Albrecht H, Meins M, Hengst U, Troncoso E, Lefort S, Kiss JZ, Petersen CC, Monard D (2004) Regulation of brain proteolytic activity is necessary for the in vivo function of NMDA receptors. J Neurosci 24:9734-9743.

Levenson J, Weeber E, Selcher JC, Kategaya LS, Sweatt JD, Eskin A (2002) Long-term potentiation and contextual fear conditioning increase neuronal glutamate uptake. Nat Neurosci 5:155-161.

Liot G, Roussel BD, Lebeurrier N, Benchenane K, López-Atalaya JP, Vivien D, 
Ali C (2006) Tissue-type plasminogen activator rescues neurones from serum deprivation-induced apoptosis through a mechanism independent of its proteolytic activity. J Neurochem 98:1458-1464.

Liu D, Cheng T, Guo H, Fernández JA, Griffin JH, Song X, Zlokovic BV (2004a) Tissue plasminogen activator neurovascular toxicity is controlled by activated protein C. Nat Med 10:1379-1383.

Liu IY, Lyons WE, Mamounas LA, Thompson RF (2004b) Brain-derived neurotrophic factor plays a critical role in contextual fear conditioning. J Neurosci 24:7958-7963.

Lu W, Bhasin M, Tsirka SE (2002) Involvement of tissue plasminogen activator in onset and effector phases of experimental allergic encephalomyelitis. J Neurosci 22:10781-10789.

Macrez R, Bezin L, Le Mauff B, Ali C, Vivien D (2010) Functional occurrence of the interaction of tissue plasminogen activator with the NR1 Subunit of $\mathrm{N}$-methyl-D-aspartate receptors during stroke. Stroke 41:2950-2955.

Macrez R, Obiang P, Gauberti M, Roussel B, Baron A, Parcq J, Cassé F, Hommet Y, Orset C, Agin V, Bezin L, Berrocoso TG, Petersen KU, Montaner J, Maubert E, Vivien D, Ali C (2011) Antibodies preventing the interaction of tissue-type plasminogen activator with $\mathrm{N}$-methyl-Daspartate receptors reduce stroke damages and extend the therapeutic window of thrombolysis. Stroke 42:2315-2322.

Madani R, Hulo S, Toni N, Madani H, Steimer T, Muller D, Vassalli JD (1999) Enhanced hippocampal long-term potentiation and learning by increased neuronal expression of tissue-type plasminogen activator in transgenic mice. EMBO J 18:3007-3012.

Mataga N, Nagai N, Hensch TK (2002) Permissive proteolytic activity for visual cortical plasticity. Proc Natl Acad Sci U S A 99:7717-7721.

Matys T, Pawlak R, Matys E, Pavlides C, McEwen BS, Strickland S (2004) Tissue plasminogen activator promotes the effects of corticotropinreleasing factor on the amygdala and anxiety-like behavior. Proc Natl Acad Sci U S A 101:16345-16350.

Miyamoto Y, Yamada K, Noda Y, Mori H, Mishina M, Nabeshima T (2002) Lower sensitivity to stress and altered monoaminergic neuronal function in mice lacking the NMDA receptor epsilon 4 subunit. J Neurosci 22:2335-2342.

Nassar T, Yarovoi S, Fanne RA, Akkawi S, Jammal M, Allen TC, Idell S, Cines DB, Higazi AA (2010) Regulation of airway contractility by plasminogen activators through $N$-methyl-D-aspartate receptor-1. Am J Respir Cell Mol Biol 43:703-711.

Nicole O, Docagne F, Ali C, Margaill I, Carmeliet P, MacKenzie ET, Vivien D, Buisson A (2001) The proteolytic activity of tissue-plasminogen activator enhances NMDA receptor-mediated signaling. Nat Med 7:59-64.

Obiang P, Maubert E, Bardou I, Nicole O, Launay S, Bezin L, Vivien D, Agin V (2011) Enriched housing reverses age-associated impairment of cognitive functions and tPA-dependent maturation of BDNF. Neurobiol Learn Mem 96:121-129.
Pang PT, Teng HK, Zaitsev E, Woo NT, Sakata K, Zhen S, Teng KK, Yung WH, Hempstead BL, Lu B (2004) Cleavage of proBDNF by tPA/plasmin is essential for long-term hippocampal plasticity. Science 306:487-491.

Pawlak R, Nagai N, Urano T, Napiorkowska-Pawlak D, Ihara H, Takada Y, Collen D, Takada A (2002) Rapid, specific and active site-catalyzed effect of tissue-plasminogen activator on hippocampus-dependent learning in mice. Neuroscience 113:995-1001.

Pawlak R, Magarinos AM, Melchor J, McEwen B, Strickland S (2003) Tissue plasminogen activator in the amygdala is critical for stress-induced anxiety-like behavior. Nat Neurosci 6:168-174.

Pawlak R, Melchor JP, Matys T, Skrzypiec AE, Strickland S (2005) Ethanolwithdrawal seizures are controlled by tissue plasminogen activator via modulation of NR2B-containing NMDA receptors. Proc Natl Acad Sci U S A 102:443-448.

Plow EF, Herren T, Redlitz A, Miles LA, Hoover-Plow JL (1995) The cell biology of the plasminogen system. FASEB J 9:939-945.

Samson AL, Nevin ST, Croucher D, Niego B, Daniel PB, Weiss TW, Moreno E, Monard D, Lawrence DA, Medcalf RL (2008) Tissue-type plasminogen activator requires a co-receptor to enhance NMDA receptor function. J Neurochem 107:1091-1101.

Seeds NW, Williams BL, Bickford PC (1995) Tissue plasminogen activator induction in Purkinje neurons after cerebellar motor learning. Science 270:1992-1994.

Seeds NW, Basham ME, Ferguson JE (2003) Absence of tissue plasminogen activator gene or activity impairs mouse cerebellar motor learning. J Neurosci 23:7368-7375.

Siegel S, Castellan NJ (1988) Nonparametric statistics for the behavioral sciences. New York: McGraw-Hill.

Tsirka SE, Gualandris A, Amaral DG, Strickland S (1995) Excitotoxininduced neuronal degeneration and seizure are mediated by tissue plasminogen activator. Nature 377:340-344.

Wang YF, Tsirka SE, Strickland S, Stieg PE, Soriano SG, Lipton SA (1998) Tissue plasminogen activator (tPA) increases neuronal damage after focal cerebral ischemia in wild-type and tPA-deficient mice. Nat Med 4:228-231.

Wu YP, Siao CJ, Lu W, Sung TC, Frohman MA, Milev P, Bugge TH, Degen JL, Levine JM, Margolis RU, Tsirka SE (2000) The tissue plasminogen activator (tPA)/plasmin extracellular proteolytic system regulates seizureinduced hippocampal mossy fiber outgrowth through a proteoglycan substrate. J Cell Biol 148:1295-1304.

Yamada K, Nagai T, Nabeshima T (2005) Drug dependence, synaptic plasticity, and tissue plasminogen activator. J Pharmacol Sci 97:157-161.

Zhuo M, Holtzman DM, Li Y, Osaka H, DeMaro J, Jacquin M, Bu G (2000) Role of tissue plasminogen activator receptor LRP in hippocampal longterm potentiation. J Neurosci 20:542-549. 